\title{
Brittleness index and its relationship with materials mechanical properties: Influence on the machinability of CAD/CAM materials
}

Thiago Soares PORTO(a) Renato Cassio ROPERTO(a) (iD Sorin Theodor TEICH ${ }^{(b)}$ (iD) Fady Fouad FADDOUL(a) (iD Fabio Antonio Piolla RIZZANTE(a) Sizenando de Toledo PORTO-NETO(c) Edson Alves de CAMPOS(c)

(a) Case Western Reserve University, School of Dental Medicine, Department of Comprehensive Care, Cleveland, Ohio, USA.

(b) Medical University of South Carolina, College of Dental Medicine, Department of Oral Rehabilitation, Charleston, South Carolina, USA.

(c) Universidade do Estado de São Paulo Unesp, Faculty of Dentistry, Department of Restorative Dentistry, Araraquara, São Paulo, Brazil.

Declaration of Interests: The authors certify that they have no commercial or associative interest that represents a conflict of interest in connection with the manuscript.

Corresponding Author:

Dr. Thiago S Porto

E-mail: txp209@case.edu

hitps://doi.org/10.1590/1807-3107bor-2019.vol33.0026

Submitted: May 30, 2018

Accepted for publication: February 16, 2019

Last revision: February 27, 2019
Abstract:The aim of this study is to evaluate the machinability of four CAD/CAM materials $(n=13)$ assessed by brittleness index, Vickers hardness, and fracture toughness and interaction among such mechanical properties. The materials selected in this in vitro study are Feldspathic ceramic [FC], Lithium-disilicate glass ceramic [LD], leucite-reinforced glass ceramic [LR], and nanofilled resin material $[R N]$. Slices were made from the blocks following original dimensions $14 \times 12 \times 3 \mathrm{~mm}(\mathrm{~L} \times \mathrm{W} \times \mathrm{H})$, using a precision slow-speed saw device and then surfaces were regularized through a polishing device. Brittleness index and fracture toughness were calculated by the use of specific equations for each one of the properties. The Vickers hardness was calculated automated software in the microhardness device. One-way Anova and Pearson's correlation were applied to data evaluation. LD obtained the highest values for brittleness index and was not significantly different from FC. LR presented statistically significant difference compared with $\mathrm{RN}$, which had the lowest mean. Vickers hardness showed LD with the highest average, and no statistical difference was found between FC and LR. RN presented the lowest average. Fracture toughness showed FC and LR not statistically different from each other, likewise LD and RN. The brittleness index, considered also as the machinability of a material, showed within this study as positively dependent on Vickers hardness, which leads to conclusion that hardness of ceramics is related to its milling capacity. In addition, fracture toughness of pre-sintered ceramics is compared to polymer-based materials.

Keywords: Dental Materials; Polymers; Prosthodontics; Hardness.

\section{Introduction}

The ongoing pursuit of excellence in aesthetic and prosthetic rehabilitation has resulted in the need to study numerous parameters. Among all factors that can influence rehabilitation; material's mechanical properties, restorations marginal fit and the cementing process ${ }^{1,2,3,4,5}$ are important keys to achieving success. For a long time gold was the preferred material for indirect restorations due to adaptation characteristics, 
polishing and laboratory handling. ${ }^{6,7}$ According to evidence from the literature, however, after ten years, ceramic restorations are very similar to gold in overall performance. ${ }^{7}$ In addition, esthetic requirements are easier to achieve with ceramic restorations. ${ }^{7}$

The accuracy of how well the prosthetic crown fits the dental preparation is one of the important determinants of rehabilitation success. The computeraided-design and computer-aided-manufacturer (CAD/CAM) technology has enormous advantage in manufacturing precise restorations. This technology reduces the distortions caused by standard methods and eliminates numerous laboratorial phases that could be complicating factors during the manufacturing process. ${ }^{8,9,10}$ Dental ceramics and polymer-based materials can be easily fabricated with CAD/CAM technology, with desirable properties due to adequate environment where it is produced. ${ }^{10,11,12}$

CAD/CAM technology provides powerful restoration and conservative preparation; however, for best performance the materials should be chosen during the treatment planning. ${ }^{5,11,12,13}$ The digital system allows preparations that are less complex and also less invasive; in addition, it provides the same strength of other treatment options. ${ }^{14,15}$ Studies have shown unexpected behavior like the higher fatigue resistance of polymer-based materials when compared with that of ceramics. The flexural modulus of polymer-based materials is very similar to that of dentin, which creates a single body in regarding mechanical behavior, and consequently polymer-based materials can be widely used. . $^{11,16,17}$

Missing is a clear gap between CAD/CAM interactions of materials' machinability and their characteristics like marginal fit after such mechanical tests as static and dynamic loading. These interactions are indispensable to clinical performance conclusions. ${ }^{12,18}$ However, the influence of fatigue and discrepancies on marginal integrity are reported for all-ceramic and gold restorations, with acceptable margins. $5,6,11,17,18$

The first mention in literature for brittleness index ${ }^{19}$ combined the results with marginal chipping factor (CF), which can be calculated only after the crowns have been milled. Ceramics have a higher brittleness index when compared with composite materials. Although some of the materials reported in the literature are no longer available, new materials have been developed in recent years. ${ }^{20,21}$ Furthermore, tests that predict the brittleness of a material before milling can be more relevant for clinicians. ${ }^{22,23}$

The chemical composition of CAD/CAM materials tested in previous in vitro studies ${ }^{19}$ led to the hypothesis that CAD/CAM polymer-based blocks may have a better clinical performance than ceramics. It is necessary, however, to conduct a deep analysis of others aspects of mechanical properties. The purpose of our investigation is to satisfy this necessity by considering the brittleness index as an important aspect of aesthetics materials and its possible interactions with other properties.

The different compositions of ceramic materials affect their mechanical properties, such as flexural strength, fracture toughness, fracture resistance, hardness, and, the main property to be investigated in this study, brittleness index. The CAD/CAM technology brings in new concepts and the necessity of new methods to predict the longevity of restorations that use machinable materials regarding susceptibility to cracks, voids, and flaws. The aim of this study is to measure the brittleness index, Vickers hardness, and fracture toughness $\left(\mathrm{K}_{\mathrm{Ic}}\right)$ of several CAD/CAM materials used with the digital system and to assess their interactions in order to better understand the behavior of the materials. The null hypothesis is that there is no correlation between the properties tested.

\section{Methodology}

Fifty-two specimens were prepared using a CAD/CAM milling unit (CEREC MC XL Sirona, Bensheim, Germany). The blocks used after milling the crowns were divided into four groups $(n=13$ each). The materials selected for the research were feldspathic ceramic (FC) as a control group, lithiuim disilicate glass ceramic (LD) in its intermediate phase, leucite-reinforced glass ceramic (LR), and nanofilled resin material (RN). The materials compositions, manufacturers, batch number, and flexural strength provided by the manufacturer are in Table 1 . The blocks surface was regularized using a slow-speed diamond saw (Isomet 4000, Buehler, Lake Bluff, 
USA), and all blocks had an approximate $3.0 \mathrm{~mm}$ of ceramic thickness with length and width kept as original for each material block (approximately $14 \mathrm{~mm}$ and $12 \mathrm{~mm}$, respectively). Their surface having been planned, with a grinding and polishing device (Metaserv 2000, Buehler, Lake Bluff, IL, USA) equipped with sandpaper cooled by water (3M ESPE, St. Paul, USA), the specimens were sequentially polished with \#180, \#250, \#360, \#400, $\# 600$, \#800, \#1200, and \#1500. In order to create the ideal smooth surface for proper data acquisition by the microhardness machine, specimens were additionally treated with a sequence of a $1 \mu \mathrm{m}$ and $0.5 \mu \mathrm{m}$ polish diamond paste (Buehler, Lake Bluff, USA) in combination with the \#1500 grit sandpaper. Specimens were then cleaned by ultrasonic water bath (Boekel Analog Model 139400, PA, USA) for fifteen minutes and air-dried.

For both tests, each specimen surface was divided in four quadrants. On each quadrant, several $49 \mathrm{~N}$ load $(\mathrm{P})$ indents with loading time of fifteen seconds were made using a Vickers hardness machine (W-402MVD Buehler - Lake Bluff, USA) at room temperature; until two acceptable indents per quadrant were selected totaling eight measures per sample and 104 per material. The following criteria was considered to have the two ideal measurements: brittleness (a) all cracks emanated from the corners of indent; (b) presence of only four radial cracks; (c) no crack chipping and; (d) no crack branching; Vickers (a) clean and visible indents; (b) no chipping around diamond indents. ${ }^{19}$

The brittleness index was calculated by measuring the crack along the vertex of the indentation in the same direction as the diagonal one. Because the cracking growth is time dependent, readings were made after 30 seconds. Using the microhardness tester, two-lines markers visible on the lens were positioned on both ends of the crack. Measurements were made and calculated by equation one: ${ }^{24}$

$$
\text { Equation }(1)-B=\gamma \mathrm{P}^{-2 / 4}(\mathrm{C} / \alpha)^{3 / 2}
$$

On the equation (1) above, $\mathrm{B}$ is the brittleness index in $\mu \mathrm{m}^{-1 / 2}$; $\mathrm{P}$ is the indentation loading $(\mathrm{N}), \gamma$ is the constant value equal to $2.39 \mathrm{~N}^{1 / 4} / \mu \mathrm{m}^{1 / 2} ; \mathrm{C}$ is the diagonal one and; $\alpha$ is the crack length diagonal one in $\mu \mathrm{m}$.

Vickers hardness was calculated by measuring the diagonal one and two distances and analyzed by the micro hardness software on the tester machine.

Twenty new specimens from each one of the materials described in Table 1 were fabricated measuring $14 \mathrm{~mm}$ of length by $3 \mathrm{~mm}$ of height and $2.5 \mathrm{~mm}$ of width. To the specimens a notch with a relationship of 1 to 3 was done along the $3 \mathrm{~mm}$ height. The protocol for specimen's preparation and the notch is described in Porto et al. ${ }^{25}$ The specimens were submitted to a three-point bending test (Test Resources, Shakopee, MN, USA) at a cross-head speed of $0.5 \mathrm{~mm} / \mathrm{min}$ until fracture. The fracture toughness was calculated with the same method described by previous publications. ${ }^{25,26,27,28}$

To identify the loading distribution on the specimens with the notch and the influence of such loading on the mechanical behavior, two calibrated $100 \mathrm{~mm}$ macro lenses F2.8D (Tokina, Tokyo, Japan) were positioned on tripods. The cameras were connected with the software VIC Snap 8 and VIC 3D (Correlated Solutions, USA) to analyze the specimens in real time during the loading. The specimens were sputtered with a white ink and black ink speckles in order to the calibrated macro lenses identify the surface loading distribution. During the three-point bending test around one hundred and fifty pictures were taken. Two pictures were chosen from each material, one

Table 1. Compositions and flexural strength of CAD/CAM materials used.

\begin{tabular}{lccc}
\hline Materials & Compositions & Flexural strength & Lot number \\
\hline Vitablocs Mark II [FC] & Feldspathic ceramic & $154 \mathrm{MPa}$ & 33410 \\
IPS e.max CAD [LD] & Lithium disilicate glass-ceramic & $130-150 \mathrm{MPa}$ & $\mathrm{T} 15004$ \\
IPS Empress CAD [LR] & Leucite-reinforced glass ceramic & $160 \mathrm{MPa}$ & $\mathrm{T} 32757$ \\
LAVA Ultimate [RN] & Nanofilled resin with silica and zirconia fillers & $150 \mathrm{MPa}$ & $\mathrm{N} 678317$ \\
\hline
\end{tabular}


at the initial loading and one just before the failure. As proposed by Lawn and Marshall an estimative of Brittleness index could be done by the relationship between Vickers hardness and $\mathrm{K}_{\mathrm{Ic}}\left(\mathrm{VH} / \mathrm{K}_{\mathrm{Ic}}\right)$. This relationship is presented in the results and compared with the $\mathrm{K}_{\mathrm{Ic}}$ data.

Statistical data were calculated by SPSS 22.0 software. Levene's test and Shapiro-Wilk test were performed to make the assumptions of homogeneity variances and data normally distributed. One-way ANOVA analysis was performed followed by Games-Howell post-hoc comparisons to find any statistically significant differences between Vickers hardness and brittleness index among the four materials. One-way ANOVA and Tukey post-hoc test were performed to find statistically significant differences among the materials tested for fracture toughness and $\mathrm{VH} / \mathrm{K}_{\mathrm{Ic}}$. Finally, the Pearson's correlation was calculated to analyze the interaction between both mechanical properties. The significance level was set at $\alpha=0.05$.

\section{Results}

The statistical analysis associated with materials' Vickers hardness and comparing the four different types of materials are reported in Table 2. A Levene's test for homogeneity of variances was used $(p<0.05)$ and not satisfied, also Shapiro-Wilk's test (normality distribution) - $(\mathrm{p}<0.05)$ and a visual inspection of their histograms, normal Q-Q plots, and box plots showed that the Vickers hardness of each ceramic is normally distributed.

For the Vickers hardness (VH) test, one-way ANOVA was performed and showed statistically significant differences among the samples $(\mathrm{p}<0.05)$. The Games-Howell post-hoc test showed statistically significant difference among ceramic materials by multiple comparisons $(p<0.05)$. LD $(6.84 \pm 0.16)$ was significantly higher than all other groups, while FC (5.97 \pm 0.22$)$, was not significantly different from LR $(5.74 \pm 0.20)$, and $\mathrm{RN}(1.02 \pm 0.06)$ was significantly lower than all other groups.

The brittleness index testing for each ceramic group was calculated by using the measurement of the loading indentation and cracking along the vertex. The descriptive statistics with materials' brittleness index are reported in Table 3. The Levene's test for homogeneity of variances was applied $(p<0.05)$ and not satisfied; also Shapiro-Wilk's test (normality distribution) - $(\mathrm{p}<0.05)$ and a visual inspection of their histograms, normal Q-Q plots, and box plots

Table 2. Means and standard deviation ( \pm SD), for first column Vickers hardness (VH - GPa); second column Brittleness index $\left(\mathrm{BI}-\mu \mathrm{m}^{-1 / 2}\right)$; third column fracture toughness $\mathrm{K}_{\mathrm{lc}}\left(\mathrm{MPa} \mathrm{m}^{1 / 2}\right)$; and fourth column Vickers hardness $(\mathrm{VH}-\mathrm{Gpa}) /$ fracture toughness $\mathrm{K}_{\mathrm{IC}}$, across the materials type.

\begin{tabular}{|c|c|c|c|c|}
\hline Variable & $\mathrm{VH}(\mathrm{GPa})$ & $\mathrm{BI}\left(\mu \mathrm{m}^{-1 / 2}\right)$ & $\mathrm{K}_{\mathrm{lc}}\left(\mathrm{MPa} \mathrm{m}^{1 / 2}\right)$ & $\mathrm{VH} / \mathrm{K}_{\mathrm{lc}}$ \\
\hline FC & $5.97( \pm 0.22)^{a}$ & $2.31( \pm 0.11)^{a}$ & $1.39( \pm 0.23)^{a}$ & $4.29( \pm 0.49)^{a}$ \\
\hline LD & $6.84( \pm 0.16)^{b}$ & $2.53( \pm 0.17)^{a}$ & $2.18( \pm 0.23)^{b}$ & $3.13( \pm 0.34)^{b}$ \\
\hline LR & $5.74( \pm 0.20)^{a}$ & $1.77( \pm 0.11)^{\mathrm{b}}$ & $1.43( \pm 0.26)^{a}$ & $4.01( \pm 0.59)^{\mathrm{a}}$ \\
\hline RN & $1.02( \pm 0.06)^{c}$ & $0.91( \pm 0.03)^{c}$ & $2.22( \pm 0.33)^{b}$ & $0.45( \pm 0.10)^{c}$ \\
\hline
\end{tabular}

"Same letters means that not statistically significant difference was found (columns).

Table 3. The descriptive statistics for Brittleness Index $\left(\mu \mathrm{m}^{-1 / 2}\right)$ across the materials type.

\begin{tabular}{lllcccc}
\hline Variable & $\mathrm{N}$ & Mean & Std. deviation & Variance & Skewness & Kurtosis \\
\hline FC & 13 & $2.31^{a}$ & 0.11 & 0.011 & 0.053 & -1.065 \\
LD & 13 & $2.53^{a}$ & 0.17 & 0.029 & -0.250 & -0.796 \\
LR & 13 & $1.77^{b}$ & 0.11 & 0.013 & 0.459 & 1.545 \\
RN & 13 & $0.91^{c}$ & 0.03 & 0.001 & 1.265 & 3.067 \\
\hline
\end{tabular}

"Same letters means that not statistically significant difference was found. 
showed that the Vickers hardness of each ceramic is normally distributed.

One-way ANOVA was also performed for the brittleness index and showed statistically significant differences among the materials $(\mathrm{p}<0.05)$. Games-Howell post-hoc test showed statistically significant difference by multiple comparisons $(p<0.05)$. The LD $(2.54 \pm 0.17)$ was not found to be statistically different from FC (2.31 \pm 0.11$)$; however, both materials were statistically significantly higher than LR $(1.77 \pm 0.11)$ and RN $(0.91 \pm 0.03)$.

Because Vickers hardness and the brittleness index are both dependent variables, Pearson's correlation was used and showed a statistically significant relationship between both dependent variables ( $p$ $<0.05$ ). There is a significant positive relationship involving Vickers hardness and the brittleness index $(\mathrm{r}[50]=0.93)$ (Figure 1).

After assumptions of homogeneity and data normally distributed one-way ANOVA was applied

Table 4. Means and standard deviation (SD) for $\mathrm{K}_{\mathrm{lc}}\left(\mathrm{MPa} \mathrm{m}^{1 / 2}\right)$ across the materials tested. The third column presents the average by Vickers hardness $(H)$ presented in table 2 and $K_{l c}$ $\left(\mathrm{H} / \mathrm{K}_{\mathrm{lc}}\right)$.

\begin{tabular}{lccc}
\hline Variable & $N$ & Mean $(S D)^{*}$ & $H / K_{\mathrm{lc}}$ \\
\hline FC & 13 & $1.39( \pm 0.23)^{a}$ & $463( \pm 50)^{a}$ \\
LD & 13 & $2.18( \pm 0.23)^{b}$ & $319( \pm 35)^{b}$ \\
LR & 13 & $1.43( \pm 0.26)^{a}$ & $416( \pm 61)^{a}$ \\
RN & 13 & $2.22( \pm 0.33)^{b}$ & $49( \pm 11)^{c}$ \\
\hline
\end{tabular}

Same letters means that not statistically significant difference was found within columns.

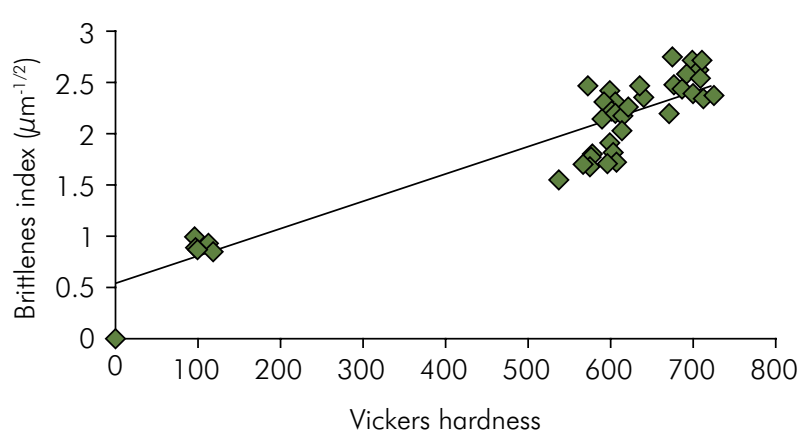

Figure 1. Pearson correlation between Vickers hardness $(x)$ and Brittleness index (y). to $\mathrm{K}_{\mathrm{Ic}}$. Statistically significant differences were found and can be observed, with the means and standard deviations in Table 4. FC did not present statistical difference compared to LR. The last two materials were significantly different from LD and RN, however, LD and RN were not statistically different between each other.

A comparison between $\mathrm{K}_{\mathrm{Ic}}$ and $\mathrm{VH} / \mathrm{K}_{\mathrm{Ic}}$ showed FC and LR with a strong relationship. Lower the fracture toughness $\left(\mathrm{K}_{\mathrm{Ic}}\right)$ higher the brittleness $\left(\mathrm{VH} / \mathrm{K}_{\mathrm{Ic}}\right)$. Conversely, RN presented higher $\mathrm{K}_{\mathrm{Ic}}$ compared to $\mathrm{FC}$ and LR but lower $\mathrm{VH} / \mathrm{K}_{\mathrm{Ic}}$ values. $\mathrm{LD}$ was not statistically significant different from $\mathrm{RN}$ in the $\mathrm{K}_{\mathrm{Ic}}$ comparisons, however, as a pre-sintered glass ceramic phase the material had a higher $\mathrm{VH} / \mathrm{K}_{\mathrm{Ic}}$ value compared to $R N$.

\section{Discussion}

The purpose of this study is to investigate and evaluate the brittleness index and the relationship with Vickers hardness, in addition the fracture toughness $\left(\mathrm{K}_{\mathrm{IC}}\right)$ of different CAD/ CAM materials, as well as the correlation between these measurements. The developments of CAD/ CAM technology combined with the new ceramic materials specifically designed for this technology are attracting the curiosity of many researchers. ${ }^{5}$ 9, 10, 29-31 The principles of chair-side CAD/CAM are becoming increasingly accepted among clinicians and universities, changing the common way of learning indirect restorations and providing access to their application by more professionals in their practices. ${ }^{10,32,33,34}$ A new skill is becoming of major importance for future dentists, improving their competence and ability to do digital restorations. Furthermore, the mechanical properties of recent CAD/CAM materials demand knowledge and familiarity from clinicians. ${ }^{10,19}$ The behavior of a variety of CAD/CAM ceramics is being introduced in new concepts such as materials' machinability, which is still not so well defined. The combination of inappropriate preparation design and the chosen materials can decrease the restoration longevity.

The first null hypothesis, that there is no correlation between properties tested, was rejected. As a result of 
the Pearson's Correlation Coefficient, a relationship of 0.93 was achieved, indicating a strong relationship between the brittleness index and Vickers hardness, with a magnitude of $86 \%$. Thus, the use of hard materials means more susceptibility to chipping, because the machinability of the materials with a high brittleness index performs more poorly than the machinability of the one with lower values. Lithium disilicate glass ceramic showed the highest values of brittleness index as well as Vickers hardness, whereas the feldspar leucite-reinforced glass ceramic showed intermediate values. As expected the nanofilled CAD/ CAM resin block presented the lowest values and thus can be considered the material with the best machinability among the ones tested. Based on the results of this study and the literature previously published, the polymer-based CAD/CAM materials will perform better in matters of machinability when compared with ceramic materials. ${ }^{19,23}$ The results also suggest that materials with high values of Vickers hardness will perform badly when they are combined with CAD/CAM technology.

The first research to discuss the relationship of brittleness index and other CAD/CAM mechanical properties has raised some significant questions regarding the use and the consequences of machining process. ${ }^{19,20,21}$ The proposal of considering chipping factor is reliable and can predict the materials' machinability; however, the chipping factor can be measured only after milling. ${ }^{19}$ Determining the relationship between the brittleness index and other mechanical properties will lead the researchers to better understand the brittleness index as well as the behavior of CAD/CAM materials. The brittleness index can indicate the susceptibility of these materials to premature edge chipping. ${ }^{19,20,21}$ Furthermore, as previously mentioned by other author polymer-based CAD/CAM materials has a lower hardness compared to ceramic materials, ${ }^{23}$ which is in accordance with the results found in this in vitro study. Also a linear relationship can be established in between the milling and the materials hardness, which is predicted by the Archard wear equation. ${ }^{23}$ So not only a faster milling is possible but also polymer-based CAD/CAM materials will offer less resistance. Furthermore, the same positive relationship found between the chipping factor (CF) and $\mathrm{BI}^{19,22}$ was also found between the $\mathrm{BI}$ and Vickers hardness. Even though it seems that the materials hardness could be another predictable of machinability, it should be always associated with other mechanical property. Finally polymerbased materials will have a great advantage of producing smoother margins that of will reduce the edge chipping and marginal discrepancies. ${ }^{19,22,23}$ Our findings can be supported by the increased chipping factor ${ }^{19}$ on the ease of milling, ${ }^{23}$ and the Pearson's correlation, which is 0.93 .

CAD/CAM technology needs easy and simple prediction of machinability. The factors that are not easy to predict are tool wear, chipping control, machining and energy forces, and surface finish and integrity, because they can be checked only after manufacturing and qualitatively analyses., ${ }^{90,29}$ Due to application of the modern way of manufacturing ceramic restorations, quantitative analysis is extremely necessary to assess the purpose of new materials.

Recent data regarding fracture resistance, calculated by the thickness of the CAD/CAM ${ }^{11}$ restorations for posterior teeth, have shown results that are comparable with our findings. The fracture resistance of nanofilled resin material was higher than that of lithium disilicate glass ceramic at a thickness of $0.5 \mathrm{~mm}$; however, when the thicknesses were increased to $3.0 \mathrm{~mm}$, they had opposite results. ${ }^{10,35}$ A strong positive linear relationships between the thickness and fracture load for lithium disilicate glass ceramic was observed. As the thickness of lithium disilicate glass ceramic was decresead, the fracture resistance was also decreased..$^{10}$ Our findings show that LD with the highest level of brittleness index, when compared with the poor performance of fracture resistance at reduced thickness, should have specific indications. Despite these indications, lithium disilicate glass ceramic is still one of the best-performing materials when used correctly.

The strong positive relationship found between the brittleness index and Vickers hardness leads to the conclusion that harder materials are the most sensitive to fracture. In addition, previous studies showed that fracture resistance is affected 
by the occlusal thickness of ceramic and composite crowns. ${ }^{36,37}$ Occlusal thickness might lead us to define which materials should be used in determined clinical situations.

Fracture toughness $\left(\mathrm{K}_{\mathrm{Ic}}\right)$ that of lithium disilicate glass ceramic has a lower resistance in a pre-sintered phase which is comparable to nanofilled resin materials. ${ }^{28}$ Furthermore, a relationship between hardness and $\mathrm{K}_{\mathrm{Ic}}\left(\mathrm{VH} / \mathrm{K}_{\mathrm{Ic}}\right)$ which could be another simple approach of brittleness as described by Lawn and Marshall ${ }^{21}$ has shown lower values for lithium disilicate compared to feldspathic ceramic and leucite-reinforce glass ceramic (Table 2). Conversely, to the brittleness index $\left(\mathrm{MPa} . \mathrm{m}^{1 / 2}\right)$ and fracture toughness presented in Tables 2. The lower value indicates less brittleness. Within the materials tested the nanofilled resin material on both brittleness calculations presented the lowest values indicating less brittleness. Despite the linear relationship only for three of the four materials tested on both methods the authors believe that the discrepancy for lithium disilicate glass ceramic is due to a plastic behavior. Such plastic behavior could be to the presintered phase which the material is presented before milling. The brittleness index measured analyzing the cracks size after the indentation is closer to the reality of the material in terms of machinability compared to the simple approach of $\mathrm{VH} / \mathrm{K}_{\mathrm{Ic}}$. The assumptions can be made based on the results previously published ${ }^{19-21,23}$ in comparisons with the data acquired within this study.

The milling process of CAD/CAM technology can cause inner flaws, voids and cracks; as we can see on Figures 2-5, the concentration of loading around a pre-crack is much higher in ceramics than in composite materials. Furthermore, the literature implies the possibility of radial cracking mode for thin ceramics. ${ }^{25,38,39,40}$ Bulk properties will be significant for ceramic materials only at $2.0 \mathrm{~mm}$ of thickness, ${ }^{35}$ however, because of such great mechanical properties, dental ceramics can be use below that thickness.

Hardness is defined as the resistance to a permanent surface indentation. As a consequence of the resistance, ceramics hardness influences polishing procedures, wear resistance, and machinability. ${ }^{41}$ The brittleness index also has a strong positive connection with the hardness property, causing it to be one of the most important features to be analyzed before choosing a restorative CAD/CAM material. Despite the positive relationship found between Vickers Hardness and $\mathrm{BI}$ and within the limitations of this in vitro study Vickers hardness cannot predict the fragility of such materials, however, as mentioned above and supported by previously publications it seems that polymer-based materials produce better margins after milling procedures.

Currently, CAD/CAM restorations are not always successful because of overall materials'
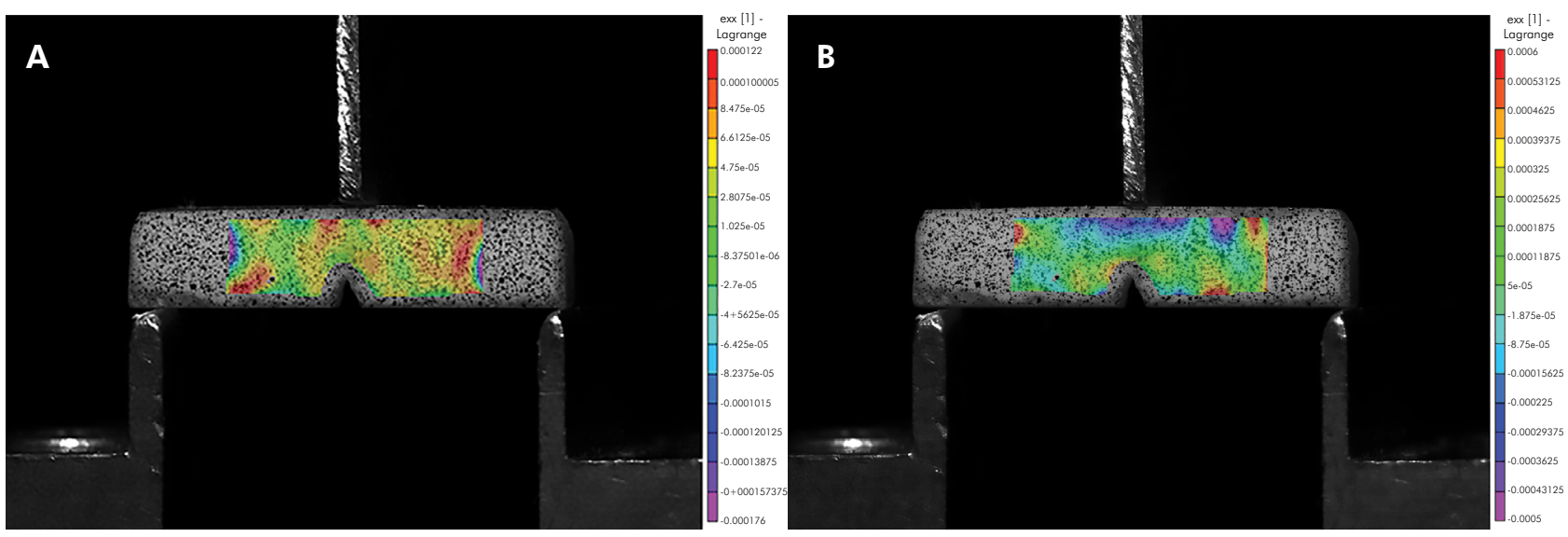

Figure 2. (a) Feldspathic ceramic strain released by the compression at the top of the specimen at the beginning of the test. (b) Below the compression area is possible to identify the strain being generated by such movement. Located above the $V$-notch a yellow orange area shows the tensile concentration at the exact moment before the specimen fracture. 


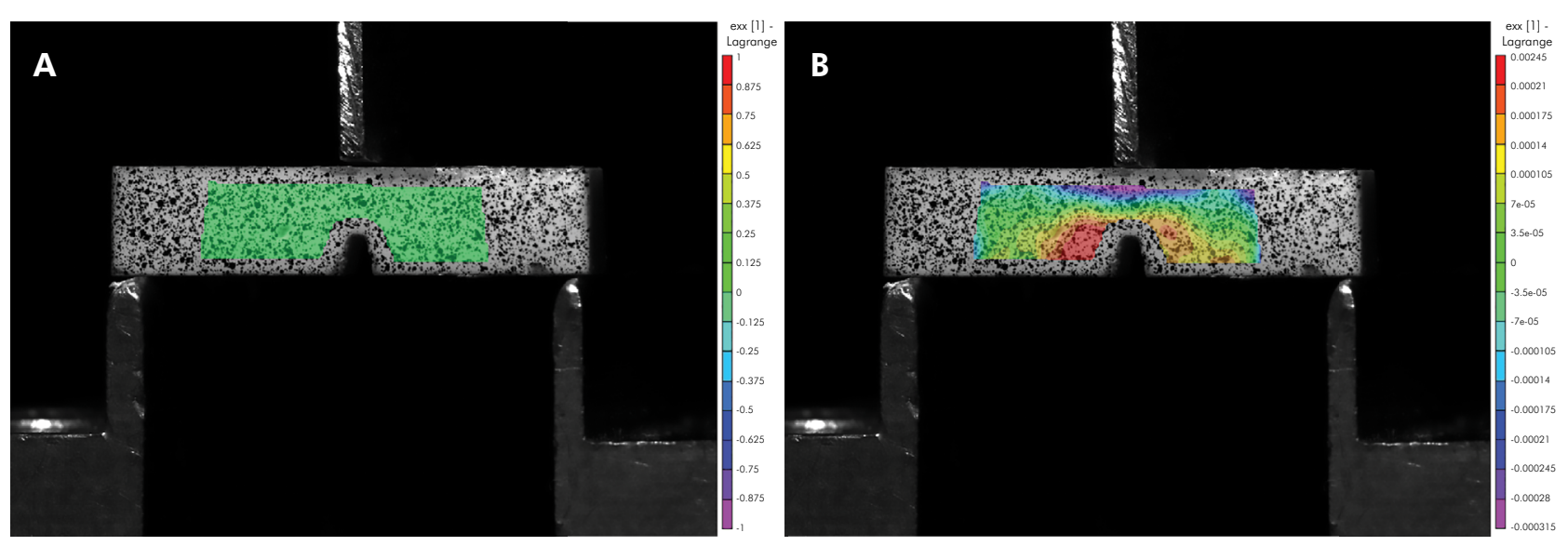

Figure 3. (a) Lithium disilicate glass ceramic represented by neutral strains on moments before initial loading. (b) The compression area can be identified by the negative forces applied at the top of the specimen. The $v$-notch is characterized by positive tensile spread over it. On both sides of the v-notch yellow orange area is present.

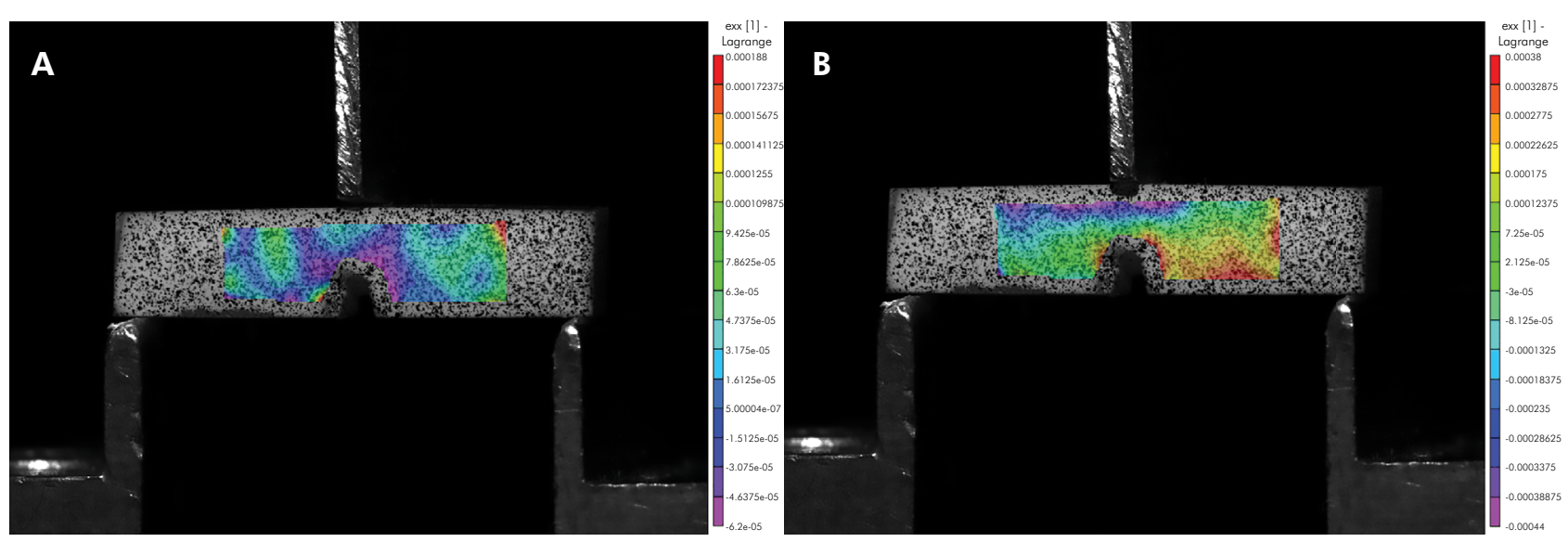

Figure 4. (a) Leucite-reinforced glass ceramic shows the initial compression area spread on the surface of the specimen. (b) As presented by the feldspathic ceramic in fig. 3(a) at the top of the V-notch the tensile is characterized by the loading concentration in sharp corners. The same pattern can be observed in this figure for leucite-reinforced glass ceramic.

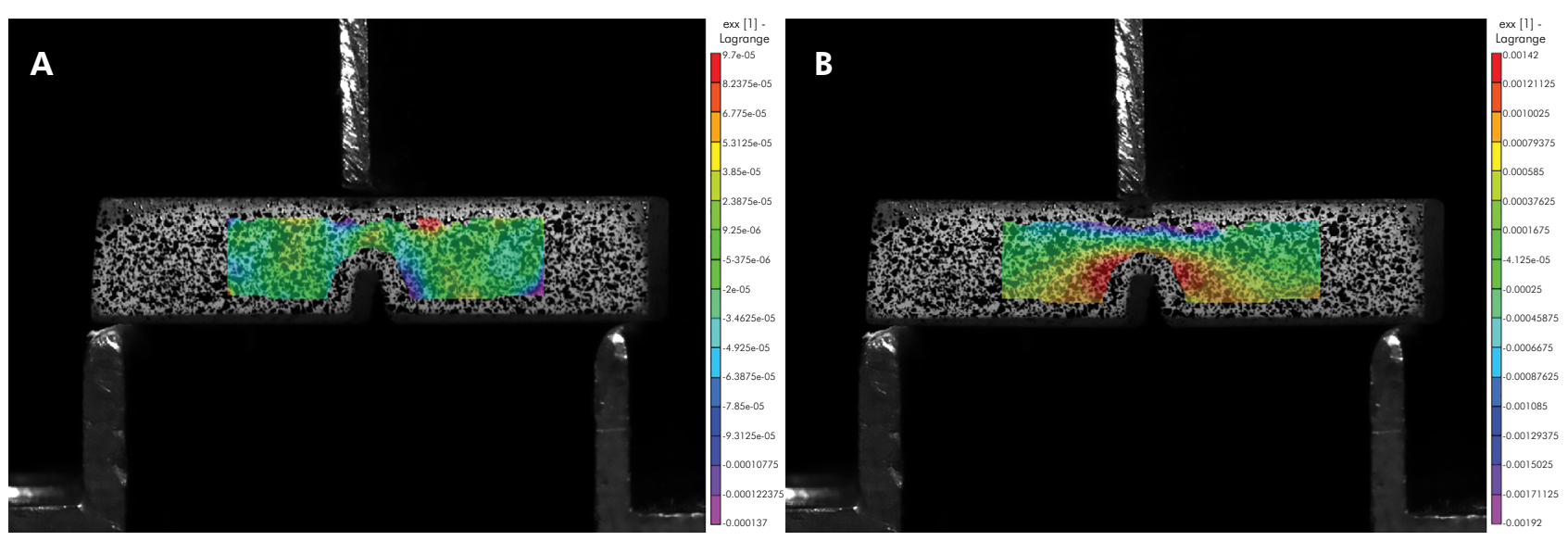

Figure 5. (a) Nanofilled resin material is characterized by scattering the strain due to plastic behavior. The initial compression can be seen just below the machine device. (b) At the moment just before the fracture scattering of the tensile stress is around the $v$-notch similar to the lithium disilicate glass ceramic showing that of unexpected plastic behavior. 
characteristics and complex restorations which are continual difficulties that every clinician is faced with. In this study, we find that an important mechanical property, such as the brittleness index, can make a real difference into the daily clinical application of these materials. Our findings should be eventually tested with different in vitro experiment, such as crown fracture resistance or fatigue, in order to develop a better understanding of the materials' behavior.

\section{Conclusion}

Based on the limitations of our findings of the Brittleness index and its relationship with Vickers hardness, the following conclusions were drawn assuming the load used to calculate:

a. There is a high and positive relationship between Brittleness index and Vickers hardness, which is above of $85 \%$. In addition, materials with higher $\mathrm{BI}$ are more susceptible to chipping;

b. Based on our findings is possible to affirm that materials, which possess elevated hardness, are more susceptible to chipping that may lead to inner cracks and flaws;

c. Milling procedures must be controlled in order to avoid premature edge chipping even though the materials are not being stressed to its maximum capacity;

d. The fracture toughness of CAD/CAM materials is not related to materials' milling capacity.

\section{Acknowledgments}

The authors would like to thanks Professor Romeu Magnani for supporting knowledge and helping with the calculation of statistical test, also Dr. Jim Stephens for editorial assistance.

\section{References}

1. Attia A, Abdelaziz KM, Freitag S, Kern M. Fracture load of composite resin and feldspathic all-ceramic CAD/CAM crowns. J Prosthet Dent. 2006 Feb;95(2):117-23. https://doi.org/10.1016/i.prosdent.2005.11.014

2. Conrad HJ, Seong WJ, Pesun IJ. Current ceramic materials and systems with clinical recommendations: a systematic review. J Prosthet Dent. 2007 Nov;98(5):389-404. https://doi.org/10.1016/S0022-3913(07)60124-3

3. Krämer N, Frankenberger R. Clinical performance of bonded leucite-reinforced glass ceramic inlays and onlays after eight years. Dent Mater. 2005 Mar;21(3):262-71. https://doi.org/10.1016/i.dental.2004.03.009

4. Pallesen U, Dijken JW. An 8-year evaluation of sintered ceramic and glass ceramic inlays processed by the Cerec CAD/CAM system. Eur J Oral Sci. 2000 Jun;108(3):239-46. https://doi.org/10.1034/i.1600-0722.2000.108003239.x

5. Guess PC, Vagkopoulou T, Zhang Y, Wolkewitz M, Strub JR. Marginal and internal fit of heat pressed versus CAD/ CAM fabricated all-ceramic onlays after exposure to thermo-mechanical fatigue. J Dent. 2014 Feb;42(2):199-209. https://doi.org/10.1016/i.jident.2013.10.002

6. Stappert CF, Chitmongkolsuk S, Silva NR, Att W, Strub JR. Effect of mouth-motion fatigue and thermal cycling on the marginal accuracy of partial coverage restorations made of various dental materials. Dent Mater. 2008 Sep;24(9):1248-57. https://doi.org/10.1016/i.dental.2008.02.005

7. Wagner J, Hiller KA, Schmalz G. Long-term clinical performance and longevity of gold alloy vs ceramic partial crowns. Clin Oral Investig. 2003 Jun;7(2):80-5. https://doi.org/10.1007/s00784-003-0205-8

8. Lorenzoni FC, Martins LM, Silva NR, Coelho PG, Guess PC, Bonfante EA, et al. Fatigue life and failure modes of crowns systems with a modified framework design. J Dent. 2010 Aug;38(8):626-34. https://doi.org/10.1016/j.jdent.2010.04.011

9. Sener-Yamaner ID, Sertgöz A, Toz-Akalın T, Özcan M. Effect of material and fabrication technique on marginal fit and fracture resistance of adhesively luted inlays made of CAD/CAM ceramics and hybrid materials. J Adhes Sci Technol. 2017; 31(1):55-70. https://doi.org/10.1080/01694243.2016.1204144

10. Andrade JP, Stona D, Bittencourt HR, Borges GA, Burnett LHJ, Spohr AM. Effect of different computer-aided design/computeraided manufacturing (CAD/CAM) materials and thicknesses on the fracture resistance of occlusal veneers. Oper Dent. $2018 \mathrm{Sep} /$ Oct;43(5):439-48. https://doi.org/10.2341/17-131-L

11. Magne P, Schlichting LH, Maia HP, Baratieri LN. In vitro fatigue resistance of CAD/CAM composite resin and ceramic posterior occlusal veneers. J Prosthet Dent. 2010 Sep;104(3):149-57. https://doi.org/10.1016/S0022-3913(10)60111-4 
Brittleness index and its relationship with materials mechanical properties: Influence on the machinability of CAD/CAM materials

12. Saridag S, Sevimay M, Pekkan G. Fracture resistance of teeth restored with all-ceramic inlays and onlays: an in vitro study. Oper Dent. 2013 Nov-Dec;38(6):626-34. https://doi.org/10.2341/12-211-L

13. Giannetopoulos S, van Noort R, Tsitrou E. Evaluation of the marginal integrity of ceramic copings with different marginal angles using two different CAD/CAM systems. J Dent. 2010 Dec;38(12):980-6. https://doi.org/10.1016/i.jdent.2010.08.011

14. Magne P, Cheung R. Numeric simulation of occlusal interferences in molars restored with ultrathin occlusal veneers. J Prosthet Dent. 2017 Jan;117(1):132-7. https://doi.org/10.1016/i.prosdent.2016.07.008

15. Guess PC, Schultheis S, Wolkewitz M, Zhang Y, Strub JR. Influence of preparation design and ceramic thicknesses on fracture resistance and failure modes of premolar partial coverage restorations. J Prosthet Dent. 2013 Oct;110(4):264-73. https://doi.org/10.1016/S0022-3913(13)60374-1

16. Kelly JR. Clinically relevant approach to failure testing of all-ceramic restorations. J Prosthet Dent. 1999 Jun;81(6):652-61. https://doi.org/10.1016/S0022-3913(99)70103-4

17. Magne P, Knezevic A. Influence of overlay restorative materials and load cusps on the fatigue resistance of endodontically treated molars. Quintessence Int. 2009 Oct;40(9):729-37.

18. Heintze SD, Cavalleri A, Zellweger G, Büchler A, Zappini G. Fracture frequency of all-ceramic crowns during dynamic loading in a chewing simulator using different loading and luting protocols. Dent Mater. 2008 Oct;24(10):1352-61. https://doi.org/10.1016/i.dental.2008.02.019

19. Tsitrou EA, Northeast SE, van Noort R. Brittleness index of machinable dental materials and its relation to the marginal chipping factor. J Dent. 2007 Dec;35(12):897-902. https://doi.org/10.1016/i.jdent.2007.07.002

20. Taira M, Yamaki M. Ranking machinability of nine machinable ceramics by dental high-speed cutting tests. J Mater Sci Lett. 1994;13(7):480-2. https://doi.org/10.1007/BF00540173

21. Lawn BR, Marshall DB. Hardness, toughness, and brittleness: an indentation analysis. J Am Ceram Soc. 1979;62(7-8):347-50. https://doi.org/10.1111/j.1151-2916.1979.tb19075.x

22. Tsitrou EA, Northeast SE, van Noort R. Evaluation of the marginal fit of three margin designs of resin composite crowns using CAD/CAM. J Dent. 2007 Jan;35(1):68-73. https://doi.org/10.1016/i.jdent.2006.04.008

23. Chavali R, Nejat AH, Lawson NC. Machinability of CAD-CAM materials. J Prosthet Dent. 2017 Aug;118(2):194-9. https://doi.org/10.1016/i.prosdent.2016.09.022

24. Sehgal J, Ito S. A new low-brittleness glass in the soda-lime-silica glass family. J Am Ceram Soc. 1998;81(9):2485-8. https://doi.org/10.1111/j.1151-2916.1998.tb02649.x

25. Porto T, Roperto R, Akkus A, Akkus O, Porto-Neto S, Teich S, et al. Mechanical properties and DIC analyses of CAD/CAM materials. J Clin Exp Dent. 2016 Dec;8(5):e512-6. https://doi.org/10.4317/iced.53014

26. Della Bona A, Corazza PH, Zhang Y. Characterization of a polymer-infiltrated ceramic-network material. Dent Mater. 2014 May;30(5):564-9. https://doi.org/10.1016/i.dental.2014.02.019

27. Cesar PF, Della Bona A, Scherrer SS, Tholey M, van Noort R, Vichi A, et al. ADM guidance-Ceramics: fracture toughness testing and method selection. Dent Mater. 2017 Jun;33(6):575-84. https://doi.org/10.1016/i.dental.2017.03.006

28. Porto TS, Roperto RC, Akkus A, Akkus O, Teich S, Faddoul FF, et al. Effect of thermal cycling on fracture toughness of CAD/CAM materials. Am J Dent. 2018 Aug;31(4):205-10.

29. Song XF, Ren HT, Yin L. Machinability of lithium disilicate glass ceramic in in vitro dental diamond bur adjusting process. J Mech Behav Biomed Mater. 2016 Jan;53:78-92. https://doi.org/10.1016/i.jmbbm.2015.08.003

30. Lebon N, Tapie L, Vennat E, Mawussi B. Influence of CAD/CAM tool and material on tool wear and roughness of dental prostheses after milling. J Prosthet Dent. 2015 Aug;114(2):236-47. https://doi.org/10.1016/i.prosdent.2014.12.021

31. Zhi L, Bortolotto T, Krejci I. Comparative in vitro wear resistance of CAD/CAM composite resin and ceramic materials. J Prosthet Dent. 2016 Feb;115(2):199-202. https://doi.org/10.1016/i.prosdent.2015.07.011

32. Mays KA, Crisp HA, Vos P. Utilizing CAD/CAM to measure total occlusal convergence of preclinical dental students' crown preparations. J Dent Educ. 2016 Jan;80(1):100-7.

33. Callan RS, Haywood VB, Cooper JR, Furness AR, Looney SW. The validity of using E4D compare's "\% comparison" to assess crown preparations in preclinical dental education. J Dent Educ. 2015 Dec;79(12):1445-51.

34. Schwindling FS, Deisenhofer UK, Porsche M, Rammelsberg P, Kappel S, Stober T. Establishing CAD/CAM in preclinical dental education: evaluation of a hands-on module. J Dent Educ. 2015 Oct;79(10):1215-21.

35. Chen C, Trindade FZ, Jager N, Kleverlaan CJ, Feilzer AJ. The fracture resistance of a CAD/CAM Resin Nano Ceramic (RNC) and a CAD ceramic at different thicknesses. Dent Mater. 2014 Sep;30(9):954-62. https://doi.org/10.1016/i.dental.2014.05.018

36. Kurtoglu C, Uysal H, Mamedov A. Influence of layer thickness on stress distribution in ceramic-cement-dentin multilayer systems. Dent Mater J. 2008 Jul;27(4):626-32. https://doi.org/10.4012/dmi.27.626

37. Ohlmann B, Gruber R, Eickemeyer G, Rammelsberg P. Optimizing preparation design for metal-free composite resin crowns. J Prosthet Dent. 2008 Sep;100(3):211-9. https://doi.org/10.1016/S0022-3913(08)60180-8 
Porto TS, Roperto RC, Teich ST, Faddoul FF, Rizzante FAP, Porto-Neto ST et al.

38. Thompson VP, Rekow DE. Dental ceramics and the molar crown testing ground. J Appl Oral Sci. 2004 12(spe):26-36. https://doi.org/10.1590/S1678-77572004000500004

39. Prakki A, Cilli R, Costa AU, Gonçalves SE, Mondelli RF, Pereira JC. Effect of resin luting film thickness on fracture resistance of a ceramic cemented to dentin. J Prosthodont. 2007 May-Jun;16(3):172-8. https://doi.org/10.1111/i.1532-849X.2006.00168.x

40. Deng Y, Lawn BR, Lloyd IK. Characterization of damage modes in dental ceramic bilayer structures. J Biomed Mater Res. 2002;63(2):137-45. https://doi.org/10.1002/ibm.10091

41. Leung BT, Tsoi JK, Matinlinna JP, Pow EH. Comparison of mechanical properties of three machinable ceramics with an experimental fluorophlogopite glass ceramic. J Prosthet Dent. 2015 Sep;114(3):440-6. https://doi.org/10.1016/i.prosdent.2015.02.024 